December 2006

\title{
NMS, and Why We Should Call It (Malignant) Catatonia
}

Robert Arnold Johnson M.D. (PGY4)

rajsep0802@yahoo.com

Follow this and additional works at: https://jdc.jefferson.edu/jeffjpsychiatry

Part of the Psychiatry Commons

Let us know how access to this document benefits you

\section{Recommended Citation}

Johnson, Robert Arnold M.D. (PGY4) (2006) "NMS, and Why We Should Call It (Malignant) Catatonia," Jefferson Journal of Psychiatry. Vol. 20 : Iss. 1 , Article 1.

DOI: https://doi.org/10.29046/JJP.020.1.006

Available at: https://jdc.jefferson.edu/jeffjpsychiatry/vol20/iss1/1

This Article is brought to you for free and open access by the Jefferson Digital Commons. The Jefferson Digital Commons is a service of Thomas Jefferson University's Center for Teaching and Learning (CTL). The Commons is a showcase for Jefferson books and journals, peer-reviewed scholarly publications, unique historical collections from the University archives, and teaching tools. The Jefferson Digital Commons allows researchers and interested readers anywhere in the world to learn about and keep up to date with Jefferson scholarship. This article has been accepted for inclusion in Jefferson Journal of Psychiatry by an authorized administrator of the Jefferson Digital Commons. For more information, please contact: JeffersonDigitalCommons@jefferson.edu. 


\section{Editorial: NMS, and Why We Should Call It (Malignant) Catatonia}

Robert Arnold Johnson, M.D. (PGY4)

The review in the current issue by Guzofski and Peralta, "Neuroleptic Malignant Syndrome, with Attention to Its Occurrence with Atypical Antipsychotic Medication: A Review," reminds me of the influence of a name. I am thinking here of the name, "neuroleptic malignant syndrome" (NMS), which was coined by Delay in 1960, following reports of "catatonic-like" states resulting from phenothiazines, and popularized through an influential review by Caroff in 1980 $(1,2)$.

A very similar syndrome, recognized as an advanced (excited, lethal, malignant, pernicious) form of catatonia had been described well before the advent of the typical antipsychotic medications. And catatonic features often are an overt feature of NMS (3-5). In addition, simple catatonia is recognized as a risk factor for NMS if typical neuroleptic is given (5). Even so, the name of NMS took on a life of its own, a meme, we might say, that began to spread from one psychiatrist's mind to another independently of the meme(s) for catatonia, despite the efforts of some to stem the tide (3). I offer as proof of this last sentence two first-hand observations. First, I find that few of my peers are aware of a link between, or similarity of, NMS and malignant catatonia (MC). Second, Doctors Guzofski and Peralta did not include much mention of MC in their original submission. And, I suspect, nothing unusual at all resides in either of these observations. A very large number of psychiatrists and psychiatry residents do not realize NMS and MC are linked concepts, that's my guess. I have been luckier myself. Two of my mentors when I was a PGY2 on the Consultation-Liaison rotation here at Jefferson, Dr. David Lynn and Dr. Dimitri Markov, taught me about MC and encouraged me to dig into its literature; as I did that, I learned about its link with NMC. And for that I have most to thank Dr. Max Fink and his colleague, Dr. Michael Alan Taylor (6, 7). They are not the only, or even the first, authors to speak of a link between MC and NMS (3), but Dr. Fink, especially, has been the most declamatory on the topic, the one most emphatic that the matter of language, the matter of the name, has a lot to do with how we clinicians behave.

His point of view is that NMS is a variant of, or a subtype of, MC: MC that happens to have been triggered by an antipsychotic medication. (The same is true, 
he believes, of serotonin syndrome: a subtype of MC, one that has been triggered by serotonergic excess.) And this view has a highly practical implication, namely, that treatment that is effective for catatonia should not be withheld from those suffering from NMS. He is thinking of benzodiazepine (lorazepam is used most often) and, should that medication prove ineffective within a few days, electroconvulsive therapy (ECT). The dose of lorazepam that is required is often quite high, so the schedule by which it is advanced will need to be aggressive (taking care not to produce oversedation or respiratory compromise, of course); it can be given parenterally, and should be in some instances (8).

So, having brought the memes of MC and NMS together in your mind, you become vigorous in the application of benzodiazepine. But it is in the early use ("early" in a relative sense) of ECT that your thinking is most changed by comparison with your thinking had the two memes remained estranged. And that's because the NMS meme, as an isolated thing, does not lead to thinking of ECT (or benzodiazepine) early on. It is modeled on another meme (by "meme"-maybe I should be speaking of a whole family of them-I mean, of course, a word or phrase or idea that appears to spread from mind to mind in the Dawkins sense, as a selfish gene might, were it possible for a gene to spread from mind to mind), that of malignant hyperthermia (MH), which brings forward first the idea of supportive care, especially with regard to control of body temperature and fluid volume, and this, of course, is a fine outcome even were MC and NMS two separate things. And next among the weapons summoned up by the NMS meme(s) is the drug dantrolene (a direct-acting muscle-relaxant that affects calcium flux from the endoplasmic reticulum), also bromocriptine (a dopamine agonist to fix the hypodopominergic state that the neuroleptic caused), amantadine (another dopaminergic drug), or both. And uncontrolled but careful clinical studies provide good support for the use of dantrolene and dopaminergic drugs in NMS $(1,5)$. It's not that their use is to be avoided, it's that ECT should not be put off long if they, as adjuncts to benzodiazepine, have not relieved the disorder within a few days. And Dr. Fink's point is this: ECT is likely to be put off too long if the concepts of NMS and MC are not linked in the clinician's mind, brought together in the one idea that the former is a special subtype of the latter. Two excellent books on catatonia, both published recently, support this opinion and document its history $(9,10)$.

No randomized studies of ECT in MC or NMS exist, but clinical experience with its good effectiveness in these conditions, which I, following Fink and several others, shall link together as one, is fairly extensive (1, 2, 5, 6, 11-14). It appears to be safe generally, but at least two patients have died as a consequence, so some caveats are in order. First is that neuroleptic must be stopped as far in advance of

Jefferson Journal of Psychiatry, Volume 20, Number 1

ISSN 1935-0783

(C) 2006 by the authors

On the Web: jdc.jefferson.edu/jeffjpsychiatry 
the procedure as possible (which should have been the case at the time of diagnosis anyway), as the two deaths mentioned were both in patients in whom neuroleptic had been continued (15). The neuroleptic in these cases was a typical one, but the caveat almost surely should extend to the newer, atypical antipsychotics also. Second is that succinylcholine should be avoided as the paralyzing agent for ECT if at all possible; this agent is known to predispose to abrupt hyperkalemia (possibly the mechanism of death for the two cases mentioned), and conditions favoring hyperkalemia are already extant in the situation (muscular injury from rigidity and high body temperature; possible renal compromise from myoglobinuria and extracellular volume depletion; possibly a direct potassium-releasing effect of ECT on skeletal muscle). The third follows from what has just been said: serum potassium should be monitored very closely and great care should be taken to ensure that extracellular volume has been repleted by adequate intravenous supple-mentation (16).

Thinking of MC, NMS, and serotonin syndrome (SS) as variations on the same theme, that of catatonia, makes it easier for me to remember how they present, mainly as the same picture with some interesting differences: the excited, prodromal phase may be missing and muscular rigidity earlier in NMS; gastrointestinal distress, and maybe myoclonic seizures, more prominent in SS. Seeing the one family makes it easier to pick up the distinctions among its members. And, speaking of families, what a large number of conditions has been reported to cause catatonia! Most of the reports are of the "benign" (simple, retarded) form (BC), but I see no reason to presume that a condition capable of causing BC could not also cause MC, as the latter may occur as an "advanced" stage, or complication, of the former. I have gathered the conditions that I have come across in the literature into two tables. The citations for these, in many instances, are in the articles or books cited in the References section.

\section{Table 1. Psychiatric Predispositions to Catatonia}

- mood disorders

mania or depression: 50\% of catatonias; $25-50 \%$ of all catatonics are manic

- $\quad$ schizophrenia \& other psychoses

$\sim 15 \%$ of catatonic adults; higher \% in children

- $\quad$ autism spectrum disorders

- $\quad$ obsessive-compulsive disorder (at least the PANDAS form)

- dissociative disorders/hypnosis

- narcolepsy

- $\quad$ periodic catatonia (a rare familial form, maybe autosomal dominant) 


\section{Table 2. Medical Predispositions to Catatonia}

(Approximately 25\% of catatonias have no psychiatric cause)

\section{Neurological}

- Von Economo's encephalitis

- HIV

- Chagas disease (acute)

- Lyme disease

- Herpes simplex

- GPI (CNS syphilis)

- $\quad$ subacute sclerosing panencephalitis

- acute disseminated encephalomyelitis

- seizure disorder (esp in children), incl postictal

- postmalarial syndrome, $\mathrm{w} / \mathrm{psychosis}$

- head injury, including subdural hematoma

- subarachnoid hemorrhage

- basilar artery thrombosis

- stroke (often cardioembolic)

- Sheehan's syndrome

- paraneoplastic encephalopathy

- periventricular diffuse pinealoma

- tumor of septum pellucidum

- subthalamic tumor, w/ hydrocephalus

- alcoholic/Wernicke encephalopathy

- multiple sclerosis

- Parkinson's disease

- progressive supranuclear palsy

- dementia with Lewy bodies

- familial cerebellar-pontine atrophy

- hereditary spinocerebellar degeneration

- tuberous sclerosis

- Creutzfeldt-Jacob disease

- bilateral globus pallidus lesions

- frontal, parietal, or thalamic lesions

- arachnoid cyst

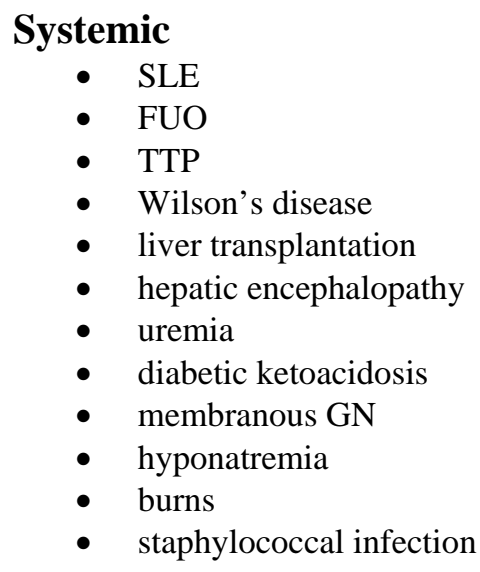

- tetanus

- tuberculosis

- infectious mononucleosis

- typhoid fever

- PANDAS

- vitamin $B_{12}$ deficiency

- hyperparathyroidism/hypoparathyroidism

- pheochromocytoma

- thyrotoxicosis

- acute intermittent porphyria

- Addison's disease/Cushing’s disease

- MEN, 1

- hereditary coproporphyria

- carcinoid tumor

- homocystinuria

- pellagra

- $\quad$ Tay-Sach disease (adult form)

\section{Toxic Effect of a Medication or Substance}

- azithromycin

- ciprofloxacin

- bupropion

- venlafaxine

- clomipramine

- methylphenidate

- lithium

- levetiracetam

- neuroleptic (NMS)

- serotonergic (SS)

- corticosteroid, ACTH

- fluorides

- baclofen

- disulfiram

- cyclosporine

- reserpine

- metoclopramide

- psilocybin

- PCP

- MDMA (ecstasy)

- opiates

- mescaline

- illuminating gas

- alcohol

- $\quad$ aspirin (overdose)

- strychnine

Jefferson Journal of Psychiatry, Volume 20, Number 1

ISSN 1935-0783 


\section{Withdrawal from a Medication}

- lorazepam, other benzodiazepine

- mixed sedative

- carbamazapine
- dopaminergic drugs

- anticholinergic drugs

- gabapentin

Hard to shake off vertigo from simply looking at these tables. Harder still to imagine the disorder in the clinician's mind, were there no unifying idea like "catatonia" to bring them together under the one roof: otherwise we would be trying to memorize, I suppose, the neuropsychiatric features one by one that each was reputed to have caused. And we would have no idea at all how to proceed with therapy. As it is, we can know this: the catatonic illness that each and every one of these disorders can, on occasion, produce is treated in exactly the same way, varying only according to its response to initial therapy, namely, to lorazepam! Of course, with the exception of withholding typical neuroleptic in all catatonias until the state is relieved, and withholding any antipsychotic, typical or atypical, in the MC variant, it doesn't hurt to treat the specific predisposition to the catatonic state, too, whenever that is possible. Such is the value of a name, the right name. Which doesn't mean the future could not bring a better one, or reveal that we'd be better off with more than one, and which names those should be.

Just why the two names, NMS and MC, fell apart and propagated separately is unclear, to me anyway. It seems that some of the important writers about them in decades past, Caroff and colleagues, and Fricchione and colleagues, took distinct care to see that separate propagation did not occur. And yet it did. (Which is why Dr. Fink has had to come to the rescue.) Perhaps psychiatry contains such variety it has trouble keeping its language from splitting into dialects that soon fracture its citizenry. Perhaps our textbook editors have under-appreciated the phenomenon of catatonia (the topic surely gets short shrift in some), owing to having succumbed to addictive properties in the format of the DSM-IV. The latter has an unstable placement for catatonia (6), apparently out of loyalty, conscious or not, to the outmoded conception that catatonia is mainly a schizophrenic condition. Perhaps NMS, flirtatious as it is with the MH meme(s), has biological cachet for those who are made anxious by the very subject of psychiatry, which is the mind.

\section{SOURCE INFORMATION}

From the Department of Psychiatry and Human Behavior, Thomas Jefferson University Hospital, Philadelphia. Address inquiries to: rajsep0802@yahoo.com. 


\section{REFERENCES}

1. Susman VL. Clinical management of neuroleptic malignant syndrome. Psychiatric Q 2001; 72:325-36

2. Lazarus A. Treatment of neuroleptic malignant syndrome with electroconvulsive therapy. J Nerv Mental Dis 1986; 174:47-9

3. Fricchione GL. Neuroleptic catatonia and its relationship to psychogenic catatonia. Biol Psychiatry 1985; 20:304-13

4. Blumer D. Catatonia and the neuroleptics: psychobiologic significance of remote and recent findings. Comprehen Psychiatry 1997; 38:193-201

5. Caroff SN, Mann SC, Keck PE Jr. Specific treatment of the neuroleptic syndrome. Biol Psychiatry 1998; 44:378-81

6. Taylor MA, Fink M. Catatonia in psychiatric classification: a home of its own. Am J Psychiatry 2003; 160:1233-41

7. Fink M, Taylor MA. Neuroleptic malignant syndrome is malignant catatonia, warranting treatments efficacious for catatonia (letter to the editor). Prog Neuropsychopharm Biol Psychiatry 2006; 30:1182-3

8. Fricchione GL, Cassem NH, Hooberman NH, Hobson D. Intravenous lorazepam in neuroleptic-induced catatonia. J Clin Psychopharm 1983; 3:338-42

9. Fink M, Taylor MA (2003). Catatonia: A Clinician's Guide to Diagnosis and Treatment. Cambridge, UK: Cambridge University Press.

10. Caroff SN, Mann SC, Francis A, Fricchione GL (2004). Catatonia: From Psychopathology to Neurobiology. Washington, DC: APPI

11. Mann SC, Caroff SN, Bleier HR, Antelo RE, Un H. Electroconvulsive therapy of the lethal catatonia syndrome: case report and review. Convulsive Therapy 1990; 6:239-47

12. Rummans TA. Medical indications for electroconvulsive therapy. Psychiatric Ann 1993; 23:27-32 
13. Ozer F, Meral H, Aydin B, Hanoglu L, Aydemir T, Oral T. Electroconvulsive therapy in drug-induced psychiatric states and neuroleptic malignant syndrome. $\mathrm{J}$ ECT 2005; 21:125-7

14. Nosijima K, Ishiguro T. Electroconvulsive therapy for the treatment of neuroleptic malignant syndrome with psychotic symptoms: a report of five cases. J ECT 1999; 15:158-63

15. Davis JM, Janicak PG, Sakkas P, Gilmore C. Electroconvulsive therapy in the treatment of the neuroleptic malignant syndrome. Convulsive Therapy 1991; 7:111-20

16. Hudcova J, Schumann R. Electroconvulsive therapy complicated by lifethreatening hyperkalemia in a catatonic patient. Gen Hosp Psychiatry 2006; 28:440-6 